\title{
Prevalence of and attitudes towards complementary therapy use for weight after breast cancer in Australia: a national survey
}

\author{
Carolyn Ee ${ }^{1 *} \mathbb{D}$, Adele Elizabeth Cave ${ }^{1}$, Dhevaksha Naidoo ${ }^{1}$ and John Boyages ${ }^{2}$
}

\begin{abstract}
Background: Weight gain is common after breast cancer (BC) treatment and may increase the risk of disease recurrence. Complementary medicine (CM) use is high amongst $B C$ patients. This paper describes the use of $C M$ from a cross-sectional self-administered survey on prevalence and management of weight after BC.

Methods: Use of CM was assessed using a question modified from the I-CAM Questionnaire. Participants were asked to rate perceived effectiveness, advantages and disadvantages, and which CM they were willing to use for weight management if there was evidence for effectiveness. The survey was emailed to members of the Breast Cancer Network Australia Survey and Review Group, the largest consumer advocacy group in Australia for people with breast cancer.

Results: There were a total of 309 responses. Three quarters had used CM in the past 12 months. One third had tried CM for weight loss. Yoga, meditation and pilates were perceived to be effective for weight loss. Perceived advantages of CMs for weight loss were the ability to improve general wellbeing, relaxation, and being nonpharmacological while disadvantages were financial cost, finding a reliable practitioner, and lack of research for effectiveness. Three quarters would be willing to try CM for weight loss if there was evidence for effectiveness, with the most popular CMs being acupuncture, relaxation, yoga, supplements, and meditation.
\end{abstract}

Conclusions: The high use of CM in this group is consistent with previous research. Our research suggests that BC survivors would use acupuncture, meditation, supplements and yoga for weight loss if supported by scientificallycredible evidence. Research into the effectiveness of these treatments on weight loss after BC is warranted.

Keywords: Breast cancer, DCIS, Complementary medicine, Overweight, Obesity, Weight gain, Australian women, National survey, Prevalence

\section{Background}

Complementary medicine $(\mathrm{CM})$ or complementary therapies refer to 'a group of diverse medical and healthcare systems, practices and products that are not generally considered part of conventional medicine' [1]. In this paper, the terms "complementary medicine", "complementary therapies" and "complementary and alternative medicine" are used synonymously. Boundaries

\footnotetext{
* Correspondence: c.ee@westernsydney.edu.au

${ }^{1} \mathrm{NICM}$ Health Research Institute, Western Sydney University, Locked Bag 1797, Penrith, NSW 2751, Australia

Full list of author information is available at the end of the article
}

within $\mathrm{CM}$ and between the $\mathrm{CM}$ domain and that of the dominant system are not always clearly defined or fixed [2]. Women with breast cancer (BC) are the most likely group to use $\mathrm{CM}$ out of all cancer patients [3] with CM use reportedly as high as $75 \%$ [4]. Patients with breast cancer using CM are mostly younger and more highly educated than non-CM users in the majority of studies. Some studies have also shown that women with breast cancer using CM had higher income than those who did not [3]. An association between $\mathrm{CM}$ use and more advanced breast cancer at diagnosis has also been found [5].

(c) The Author(s). 2019 Open Access This article is distributed under the terms of the Creative Commons Attribution 4.0 International License (http://creativecommons.org/licenses/by/4.0/), which permits unrestricted use, distribution, and reproduction in any medium, provided you give appropriate credit to the original author(s) and the source, provide a link to the Creative Commons license, and indicate if changes were made. The Creative Commons Public Domain Dedication waiver (http://creativecommons.org/publicdomain/zero/1.0/) applies to the data made available in this article, unless otherwise stated. 
Weight gain is common after a breast cancer diagnosis and may increase the risk of disease recurrence and allcause mortality, increase the burden of chronic disease from obesity-related disorders such as cardiovascular disease and diabetes, and have a significantly negative impact on quality of life [6]. Weight gain after a BC diagnosis is thought to be multifactorial and related to the use of systemic treatment as well as changes in lifestyle $[6,7]$. There is emerging evidence for the use of some CM to assist weight loss in the general population. However, little is known about the use of CM for weight loss amongst women with $\mathrm{BC}$, making it important to understand patterns and drivers of use of CM amongst women with $\mathrm{BC}$.

The aim of this national survey was to describe the use of CM for weight management after $\mathrm{BC}$ in Australian women

\section{Methods}

\section{Study design and inclusion criteria}

We conducted a cross-sectional self-administered anonymous survey using Qualtrics online survey software [8]. Any woman living in Australia who self-identified as having $\mathrm{BC}$ was eligible to complete the survey. We recruited mainly from the Breast Cancer Network Australia (BCNA) Review and Survey Group ( $n=1857)$, representing approximately $2 \%$ of all BCNA members, who had agreed to receive emails about research studies. BCNA is the largest breast cancer advocacy group in Australia, and their Review and Survey Group is one of the largest breast cancer consumer groups available for research, representing an important source of feedback for the research community. By limiting research at BCNA to the Review and Survey group, researchers have access to women who are engaged in the research process, while the remainder of BCNA members are protected from frequent research requests. We also recruited through other online communities (women's health organization social media pages and online breast cancer support groups in Australia).

The survey was emailed on December 5th, 2017 and a reminder email was sent to 1835 members on January 15th, 2018 (Appendix). Ethics approval was provided by the Human Research Ethics Committee, Western Sydney University (H12444, Oct 2017).

\section{Survey instrument}

This study is drawn from a larger study exploring the prevalence, predictors and management of weight after breast cancer amongst women in Australia (Ee C, Cave A, Naidoo D, Boyages J. Weight before and after a diagnosis of breast cancer or Ductal Carcinoma In Situ: a national Australian survey/under review). The survey was developed after reviewing previous literature on weight after breast cancer and was later revised to include feedback from six BCNA representatives and several health researchers. The 60 -item survey included questions on the sociodemographic characteristics, medical details such as diagnosis and treatment, lifestyle habits, and weight and weight management of women (see Appendix for further details). In this paper, we report on complementary therapy use for any condition and for weight management. Further analyses from our data will include predictors of weight gain in our sample, but are not reported in this manuscript.

\section{Weight after diagnosis}

Women were asked to self-report their weight in kilograms $(\mathrm{kg})$ at the time of diagnosis, and current weight and height (in meters). Body Mass Index (BMI) was calculated from weight and height as weight/height ${ }^{2}$ and reported in $\mathrm{kg} / \mathrm{m}^{2}$. BMI was classified as underweight $(<20 \mathrm{~kg})$, healthy weight (BMI $\geq 20$ and $<25$ ), overweight (BMI $\geq 25$ and $<30)$ and obese $($ BMI $\geq 30)$ [9]. The pattern of weight since diagnosis was also assessed as "gained weight overall", "lost weight overall", "weight stable" or "weight has fluctuated a great deal". Weight at diagnosis was reported by $90 \%$ of total respondents (277 women) and current weight by $95 \%$ of respondents (293 women).

\section{Complementary therapies}

Women were asked about their use of CM for any condition, and also specifically for weight loss, in the past 12 months. This question was modified from the International Questionnaire to Measure.

Use of Complementary and Alternative Medicine (ICAM Questionnaire) [10] which is culture-neutral and does not promote one modality over another although we have slightly modified the terminology to suit an Australian population [10]. CM use is divided into visits to complementary therapists (e.g. acupuncturists, chiropractors), use of herbal medicine and dietary supplements (defined as vitamins, minerals, herbs and antioxidants), and of self-help practices (e.g. yoga). Participants were asked to rate the perceived usefulness of chosen CM by selecting one option on a 7-point Likert scale ranging from 'strongly agree' to 'strongly disagree', in response to the statement "I found this therapy to be effective for my condition and/or helpful for me overall" or "I found this therapy to be effective in helping me manage my weight". We further trichomotised the responses into 'strongly agree/agree (effective)', 'somewhat agree/neither agree nor disagree (neutral)', and 'somewhat disagree, disagree, strongly disagree (not effective)'.

Data on visits to conventional health practitioners (general practitioner/primary care physician, oncologist, allied health) over the past 12 months were also 
collected. Finally, we asked women about the perceived advantages and disadvantages of using $\mathrm{CM}$ for weight management and which $\mathrm{CM}$ they were willing to use for weight management if there was research evidence to demonstrate effectiveness. Women were given a selection of responses to choose from and could also provide free text answers for additional comment.

\section{Statistical analysis}

IBM SPSS statistics package version 23 [11] and Stata statistical software [12] were used to analyse the data presented in this report. We used descriptive statistics to present the majority of the data, and Pearson's chisquare to identify associations between weight gain and $\mathrm{CM}$ use, and advanced breast cancer (metastatic or inflammatory) and $\mathrm{CM}$ use. To explore differences in demographic characteristics between respondents who were from the BCNA Review and Survey group vs non BCNA respondents, we used Pearson's chi-square, linear regression and independent samples t-tests.

\section{Results}

\section{Survey response}

Of the 1857 BCNA members, 283 (15\%) responded to the survey. A further 26 women responded to the survey from other channels giving a total of 309 responses.

\section{Sample characteristics}

Demographic and clinical characteristics of respondents are described in Table 1 . The majority of women were Caucasian $(92.5 \%, n=285)$ with a mean age of 59.1 years $(S D=9.5$, range $33-78, n=298)$. Characteristics were similar across BCNA members and non-BCNA respondents except that there was a higher proportion of women in the non-BCNA group who were selfemployed (23\% vs $10 \%$ ) and in the BCNA group who were retired (33\% vs $23 \%$ ), however this difference was not statistically significant on Pearson's chi-square testing, $X^{2} \quad(7, N=307)=6.9912, p=0.430$. There was also no statistically significant correlation between age and type of employment apart from doing voluntary work $(p=0.05)$, and no difference in age between BCNA and non-BCNA respondents $(p=0.0759)$. The majority of women $(82 \%, n=252)$ had been diagnosed with nonmetastatic $\mathrm{BC}$. The mean time since diagnosis of $\mathrm{BC}$ was 8.2 years (SD 5.12, range $1-32$ years) and mean age at diagnosis was 50.9 years $(\mathrm{SD}=9.02$, range $29-74)$. The majority of women were diagnosed either Ductal Carcinoma in Situ or localized breast cancer. There was no association between more advanced cancer and use of any complementary medicine, $X^{2}(1, N=289)=$ $2.1218, p=0.145$.

\section{Weight change}

Mean BMI at time of diagnosis was $26.23 \mathrm{~kg} / \mathrm{m}^{2}(n=$ 270, SD 5.43) and at time of survey was $28.02(n=285$, SD 5.88). Just under half of women (48.5\%) were overweight or obese at time of diagnosis, but by the time of the survey this proportion had risen to $67.3 \%$. This increase was most marked for women who were obese, from $17.04 \%$ at diagnosis to $31.93 \%$ at the time of the survey. The majority of respondents (63.70\%) reported they had gained weight overall after diagnosis. Of the women who reported gaining weight overall and for whom we had complete weight data $(n=175)$, average weight gain was $9.07 \mathrm{~kg}$.

\section{Complementary therapy use for any health condition}

Figure 1 describes reported CM use for any health condition and associated perceived effectiveness, and Table 2 describes reasons for CM use and information sources. About three quarters of women (201 or $73.4 \%$ ) had used a CM for any health condition in the past 12 months. The top five CMs used to treat any health condition were relaxation techniques, yoga, meditation, prayer and massage. The top three reasons for $\mathrm{CM}$ use were to improve general physical wellbeing (80\% of CM users), reduce stress/improve psychological wellbeing (62\% of $\mathrm{CM}$ users), and to treat a condition unrelated to cancer (37\% of CM users). The treatments that women found most effective were massage, yoga, meditation, acupuncture, and relaxation with more than $50 \%$ of women who had used these therapies strongly agreeing or agreeing that the treatments had been effective. Most women sought information on CM from friends and family, followed by complementary therapists, the internet, GPs, and specialists. There was no association between $\mathrm{CM}$ use and whether women had gained $>5 \%$ of weight overall or had maintained a stable weight, $X^{2}(1, N=$ 277) $=0.2017, p=0.653$.

\section{Complementary therapy use for weight loss}

Figure 2 describes the number of women who had tried a CM for weight loss, and perceived effectiveness. A small number $(n=85$, or $31 \%$ who completed the entire survey) of women had tried CM in the last 12 months for weight loss. The most popular therapies were supplements, yoga, relaxation techniques, massage and meditation. More than $40 \%$ of women who had tried yoga, meditation or pilates agreed or strongly agreed it had been helpful in relation to weight loss, however the majority of women felt neutral about the effectiveness of the therapies they had tried. Table 3 describes the perceived advantages and disadvantages of using $\mathrm{CM}$ for weight management. The most commonly selected perceived advantages of using CMs for weight loss were the ability to improve general wellbeing, relaxation, and 
Table 1 Demographic and clinical characteristics of survey respondents

\begin{tabular}{|c|c|c|}
\hline Description & $\mathrm{N}$ (responses) & Percentag \\
\hline \multicolumn{3}{|l|}{ State $(n=309)$} \\
\hline Australian Capital Territory & 14 & $4.53 \%$ \\
\hline New South Wales & 91 & $29.45 \%$ \\
\hline Northern Territory & 0 & $0.00 \%$ \\
\hline Queensland & 48 & $15.54 \%$ \\
\hline South Australia & 28 & $9.06 \%$ \\
\hline Tasmania & 3 & $0.97 \%$ \\
\hline Victoria & 95 & $30.74 \%$ \\
\hline Western Australia & 30 & $9.71 \%$ \\
\hline \multicolumn{3}{|l|}{ Education $(n=307)$} \\
\hline High school- year 10 & 30 & $9.77 \%$ \\
\hline High school- year 12 & 35 & $11.40 \%$ \\
\hline Vocational College & 55 & $17.91 \%$ \\
\hline Bachelor's degree & 90 & $29.32 \%$ \\
\hline Postgraduate degree & 97 & $31.60 \%$ \\
\hline \multicolumn{3}{|l|}{ Ethnicity $(n=308)$} \\
\hline European/Anglo Saxon/Caucasian & 285 & $92.53 \%$ \\
\hline Asian & 5 & $1.62 \%$ \\
\hline $\begin{array}{l}\text { Oceanic (incl. Australian and } \\
\text { New Zealand first peoples, } \\
\text { Polynesian and Micronesian) }\end{array}$ & 13 & $4.22 \%$ \\
\hline North/South/Central American & 2 & $0.65 \%$ \\
\hline Mixed ethnicity & 2 & $0.65 \%$ \\
\hline Indian & 1 & $0.33 \%$ \\
\hline \multicolumn{3}{|l|}{ Employment $(n=308)$} \\
\hline Employee & 140 & $45.46 \%$ \\
\hline Self-employed & 33 & $10.71 \%$ \\
\hline $\begin{array}{l}\text { Home duties/caring for children } \\
\text { or family }\end{array}$ & 15 & $4.87 \%$ \\
\hline $\begin{array}{l}\text { In education (going to school, } \\
\text { university, etc.) }\end{array}$ & 4 & $1.30 \%$ \\
\hline Doing voluntary work & 10 & $3.25 \%$ \\
\hline Unable to work because of illness & 6 & $1.95 \%$ \\
\hline Unable to work for other reasons & 1 & $0.32 \%$ \\
\hline Retired & 99 & $32.14 \%$ \\
\hline \multicolumn{3}{|l|}{ Relationship Status ( $\mathrm{n}=309$ ) } \\
\hline Single & 39 & $12.62 \%$ \\
\hline $\begin{array}{l}\text { Married/De Facto } \\
\text { (living with partner) }\end{array}$ & 230 & $74.43 \%$ \\
\hline $\begin{array}{l}\text { In a relationship but not living } \\
\text { with partner }\end{array}$ & 7 & $2.27 \%$ \\
\hline Divorced/separated & 24 & $7.77 \%$ \\
\hline Widowed & 9 & $2.91 \%$ \\
\hline \multicolumn{3}{|l|}{ Diagnoses $(n=308)$} \\
\hline Ductal Carcinoma In Situ (DCIS) & 33 & $10.71 \%$ \\
\hline
\end{tabular}

Table 1 Demographic and clinical characteristics of survey respondents (Continued)

\begin{tabular}{lll}
\hline Description & $\mathrm{N}$ (responses) & Percentage \\
\hline Localised breast cancer & 252 & $81.82 \%$ \\
Metastatic breast cancer & 14 & $4.55 \%$ \\
Inflammatory breast cancer & 2 & $0.65 \%$ \\
Other including second primary & 7 & $2.27 \%$ \\
\hline
\end{tabular}

being non-pharmacological. The major disadvantages reported were financial cost, finding a reliable practitioner, and lack of research for effectiveness.

When asked which therapies they would try if there was research to demonstrate effectiveness for weight loss, almost half of women indicated they would be willing to try acupuncture/acupressure, followed by relaxation techniques, yoga, supplements, and meditation (Fig. 3). Overall, around three quarters of respondents (237 women) would be willing to try a CM for weight loss if there was demonstrated scientific evidence for its effectiveness.

\section{Discussion}

In our survey, we found high rates of $\mathrm{CM}$ use for any condition, but lower rates of use for weight management, with limited perceived effectiveness of the therapies that had been tried. Women in our survey cited barriers to use of $\mathrm{CM}$ for weight management after $\mathrm{BC}$ including lack of research for effectiveness. However, $\mathrm{CM}$ was seen to be advantageous in improving general wellbeing, providing relaxation, and being non-pharmacological. Three quarters of women would consider a $\mathrm{CM}$ if there was evidence for effectiveness (particularly, acupuncture/acupressure, relaxation techniques, yoga, supplements, and meditation).

Almost three quarters of women in our sample had used a CM in the preceding 12 months. This is consistent with evidence from a recent systematic review reporting prevalence of up to $87 \%$ in Australia [3]. CM users in our sample cited reasons for use such as improving general physical wellbeing, reducing stress/improving psychological wellbeing and treating conditions unrelated to cancer. Similarly, in another survey, BC survivors use CMs to "help healing, to promote emotional health, and to cure cancer" [3]. The most recent survey conducted in Australia on CM use in $\mathrm{BC}$ survivors reported women believed that CMs improved their wellbeing, boosted their immune system, reduced side effects of treatments, reduced symptoms of cancer, treated the cancer, and prevented recurrence [13]. Cancer patients mostly report using $\mathrm{CM}$ in an adjunctive manner, e.g. to improve overall general health and wellbeing [14] or to minimize adverse effects from 


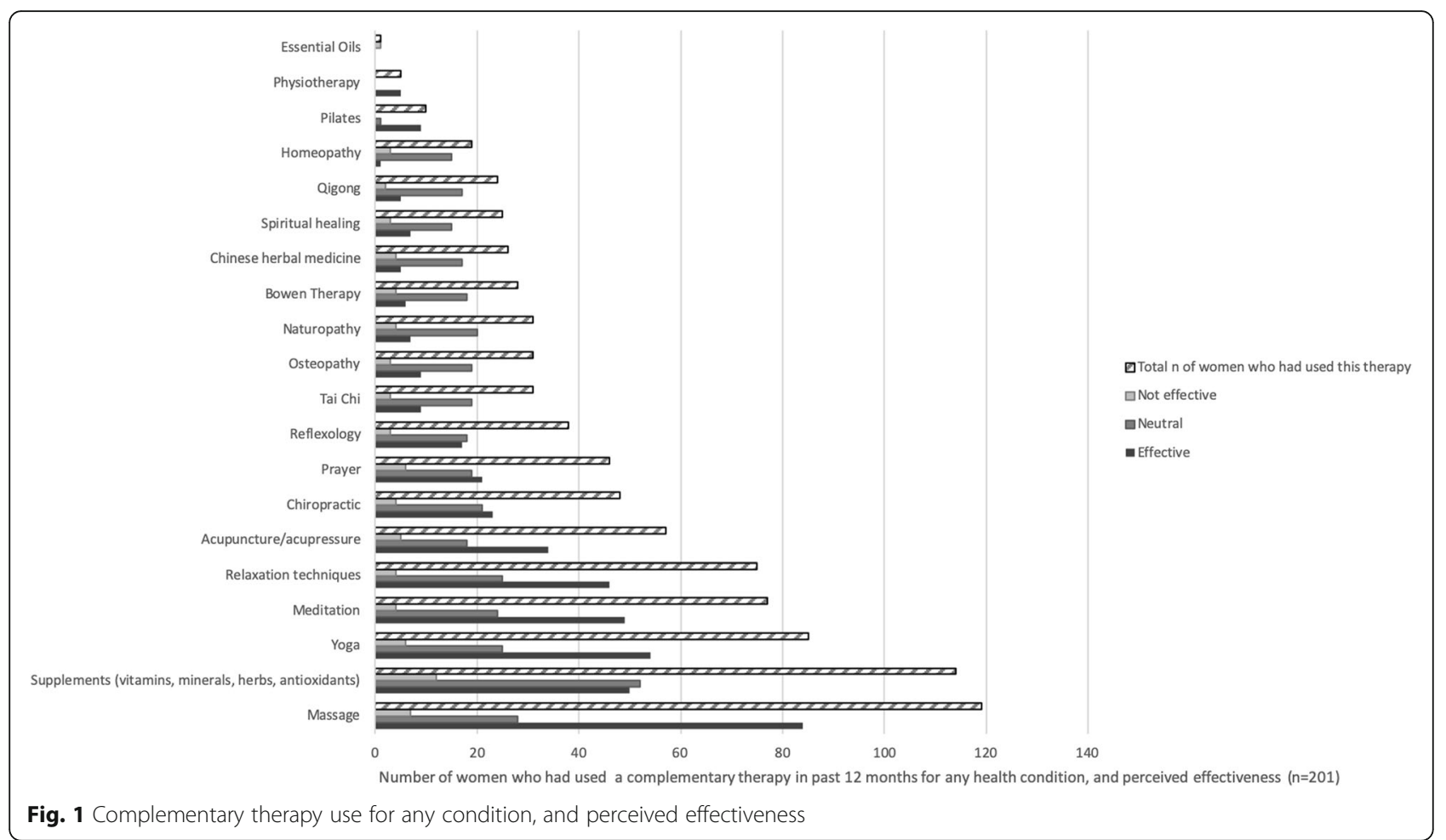

Table 2 Complementary therapy use: Reasons and information sources

\begin{tabular}{lll}
\hline Description & Number & Percent \\
\hline Reasons for CM use ( $n=201)$ & & \\
Improve physical wellbeing & 159 & $79.10 \%$ \\
$\quad$ Stress management/improve & 124 & $61.69 \%$ \\
psychological wellbeing & & \\
Improve a non-cancer related & 75 & $37.31 \%$ \\
symptom or condition & & \\
Improve a side effect related to & 51 & $25.37 \%$ \\
cancer treatment & & \\
Boost immune system & 40 & $19.90 \%$ \\
Prevent recurrence & 39 & $19.40 \%$ \\
Improve a cancer-related symptom & 29 & $14.43 \%$ \\
Source of CM information ( $n=184)$ & & \\
Friend/family & 70 & $38.04 \%$ \\
Complementary therapist & 48 & $26.09 \%$ \\
Internet & 46 & $25.00 \%$ \\
GP & 43 & $23.37 \%$ \\
Specialist & 28 & $15.22 \%$ \\
Media (TV, newspapers, & 23 & $12.50 \%$ \\
magazines, radio) & & \\
Nurse & 8 & $4.35 \%$ \\
Social media & & \\
Pharmacist & $23 \%$ \\
\hline
\end{tabular}

$C M=$ Complementary medicine conventional treatment and to prevent further illness [15]. Collectively, these data suggest that women with $\mathrm{BC}$ seek a range of therapeutic options to optimize all aspects of their health and wellbeing in a holistic manner, particularly to improve psychological wellbeing.

In our sample, the most commonly used CMs for any reason were nutraceutical supplements, massage, meditation and yoga which is consistent with what is reported in the literature [3]. Some studies specifically reported whole medical systems such as naturopathic or traditional Chinese medicine most commonly used by $\mathrm{BC}$ patients $[16,17]$. Of interest, although nutraceutical supplements were the most commonly used therapy, about half of women perceived their effectiveness to be neutral. The therapies with the highest perceived effectiveness included massage, acupuncture/acupressure, relaxation techniques and yoga.

A smaller proportion (31\%) of women had used $\mathrm{CM}$ for weight management. In non-cancer populations, studies suggest that up to $70 \%$ of people with obesity use CM $[18,19]$ particularly if they are female [18]. People with metabolic syndrome are also higher users of CM [19] compared to people without metabolic syndrome. However, it is unclear if the high use of $\mathrm{CM}$ in people without obesity indicates use specifically for weight management, or if $\mathrm{CM}$ are used for other reasons $[18,19]$. We could not find any literature describing the prevalence of use of $\mathrm{CM}$ for 


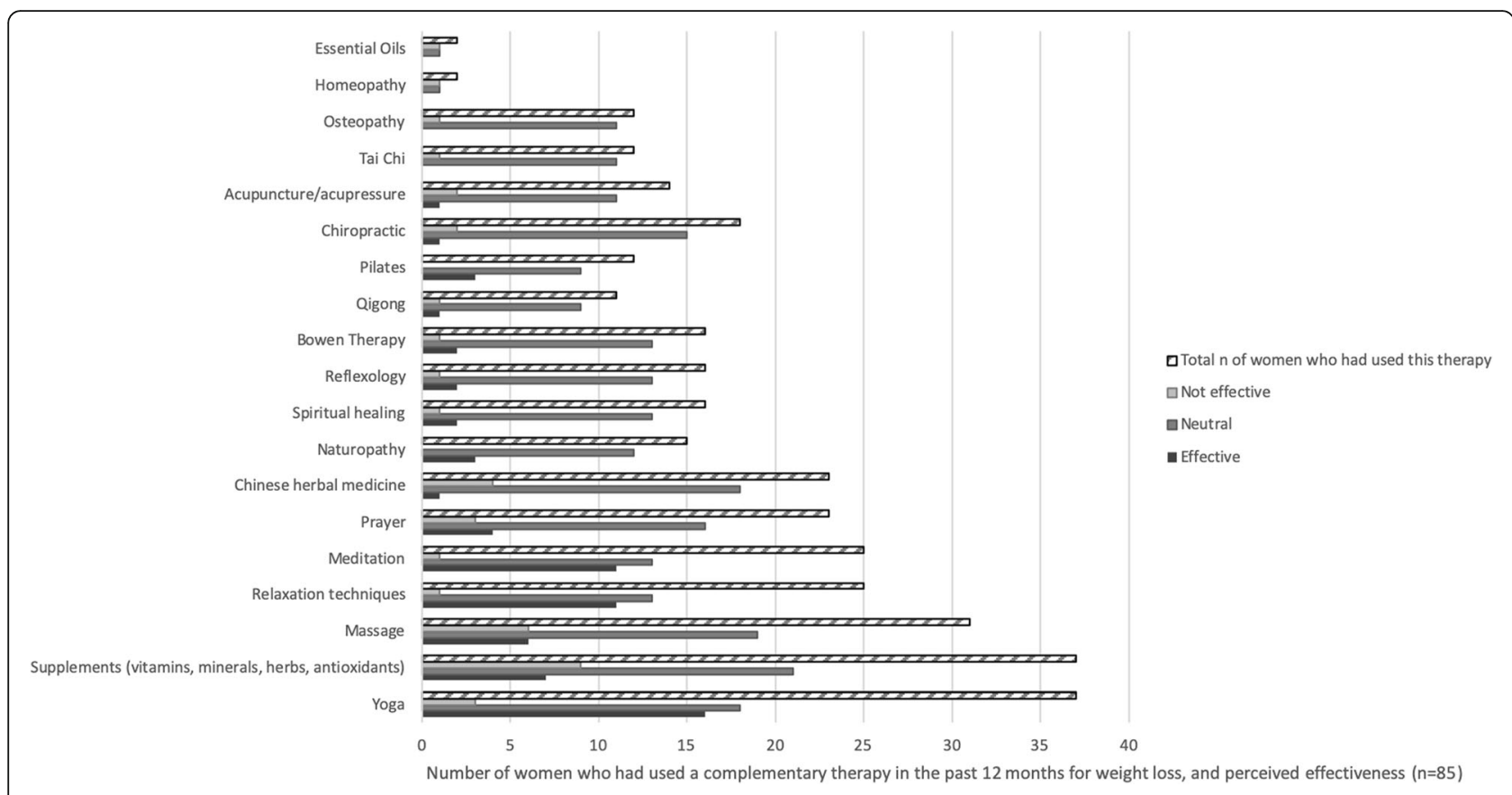

Fig. 2 Complementary therapy use for weight loss, and perceived effectiveness

Table 3 Perceived advantages and disadvantages of using complementary therapies for weight management

\begin{tabular}{lll}
\hline Description & Number & Percent \\
\hline Perceived advantages of CM use $(n=183)$ & 139 & $75.96 \%$ \\
Improves general wellbeing & 105 & $57.38 \%$ \\
Reduces stress/is relaxing & 101 & $55.19 \%$ \\
Not needing to use drugs/medication & 64 & $34.97 \%$ \\
Can treat other symptoms at the same time & 57 & $31.15 \%$ \\
Holistic approach & 56 & $30.60 \%$ \\
Non-surgical/not needing to have an operation & 57 & $20.22 \%$ \\
Agree with the philosophy behind the therapy & 37 & $9.84 \%$ \\
Already using it & 18 & \\
Perceived disadvantages of CM use ( $n=214)$ & & $59.81 \%$ \\
Financial cost & 128 & $57.94 \%$ \\
Lack of research to show it is effective & 124 & $46.26 \%$ \\
Finding a reliable practitioner & 99 & $27.10 \%$ \\
Interactions with medications & 58 & $24.77 \%$ \\
Cannot find reliable information & 53 & $17.29 \%$ \\
Time commitment & 37 & $6.54 \%$ \\
Side effects of treatment & 1 & $6.07 \%$ \\
My GP/specialist does not support its use & 13 & $1.40 \%$ \\
Don't work/don't trust & 3 & $0.93 \%$ \\
Unsure & 2 & $0.47 \%$ \\
Motivation to continue & 1 & \\
Too many treatments already & & \\
Goes against my beliefs & 13 & \\
\hline
\end{tabular}

$G P=$ General Practitioner/family physician/primary care physician weight management in $\mathrm{BC}$ survivors. The therapies were mostly perceived as neutral in terms of effectiveness, with the exception of yoga and meditation, which greater than $40 \%$ of our sample thought were effective treatments.

One of the most commonly cited barriers to using CM in our study was the perceived lack of evidence for effectiveness. Similarly, in a qualitative study, the most common reason given for deciding not to use $\mathrm{CM}$ amongst cancer survivors was a lack of meaningful information regarding safety and efficacy [15]. However, around three quarters of women in our sample indicated that they would try a CM to assist with weight management should there be sufficient evidence demonstrating effectiveness. The most commonly cited CM that would be chosen in this situation was acupuncture/acupressure, with around half of women willing to trial these modalities, followed by relaxation techniques, yoga, supplements, and meditation. Indeed, acupuncture shows promise in the treatment of obesity and overweight in general populations. A recent meta-analysis reported that acupuncture, in particular auricular acupuncture and electro-acupuncture, was more efficacious than sham acupuncture for reducing BMI (MD $\left.-0.47 \mathrm{~kg} / \mathrm{m}^{2}\right)$ as well as body fat mass (MD $-0.66 \mathrm{~kg}$ ), waist circumference $(\mathrm{MD}-2.02 \mathrm{~cm})$ and hip circumference $(\mathrm{MD}-2.74$ $\mathrm{cm}$ ) but not for reducing body weight overall [20]. Mechanistic studies have suggested multiple responses to acupuncture including appetite suppression [21, 22], modulation of leptin and ghrelin [23-25] and improved 


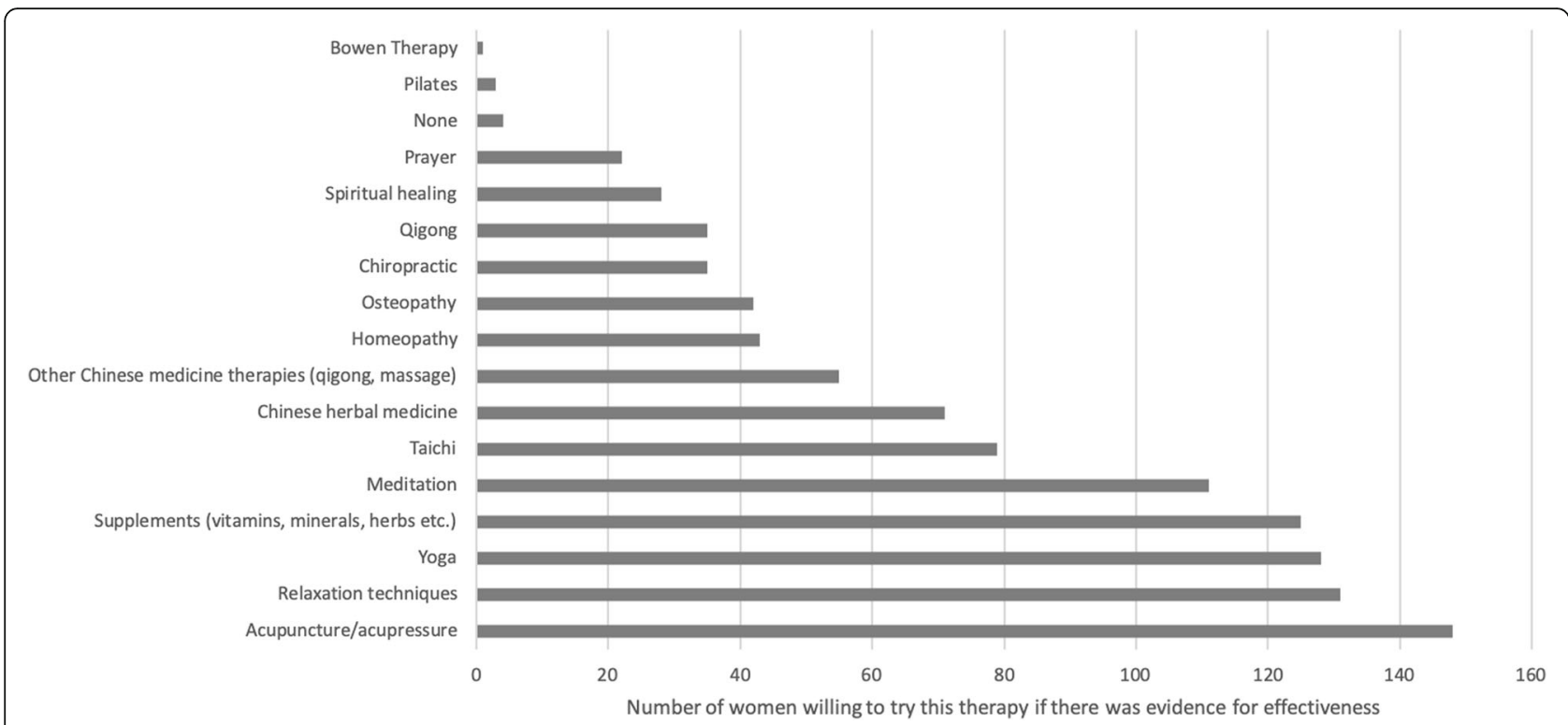

Fig. 3 Complementary therapies that respondents would be willing to try if effective for weight loss

insulin sensitivity [26-31]. Further, acupuncture may alleviate co-morbid anxiety symptoms in people with obesity [23, 32, 33]. Given that acupuncture is a relatively safe treatment [34-36] and may have additional benefits in women with $\mathrm{BC}$ including relief of chemotherapyinduced peripheral neuropathy [37], aromatase-inhibitor induced arthralgia [38, 39], menopausal symptoms [40] and lymphoedema [41], it may represent a useful adjunctive therapy that can assist women in managing a number of bothersome symptoms and manage weight. To the best of our knowledge, there are no studies examining the effectiveness of acupuncture for weight loss in women with $\mathrm{BC}$, and such research appears warranted.

Women in our sample were also willing to trial meditation, yoga and nutritional supplements for weight management. In non-BC populations, limited evidence suggests that mindfulness meditation may help people improve eating behaviours (such as reducing the amount of emotional eating), increase physical activity, and reduce anxiety and stress [42-47] while two pilot studies using mindfulness-based techniques for weight management in women with $\mathrm{BC}$ have reported promising findings for weight loss and eating behaviors [48, 49]. Again in non-BC populations, yoga may be effective for reduction of BMI compared with usual care (SMD -0.99) [50], while a pilot trial in women with $\mathrm{BC}$ reported a reduction in waist circumference of $3.1 \mathrm{~cm}$ and improvements in quality of life [51]. A range of nutraceutical supplements may have modest effects on weight [52-55]. Given the interest in using these complementary modalities to assist weight loss, and the potential for additional benefits such as for mental health, further clinical research into the effectiveness and efficacy of these low risk mind-body interventions as an adjunct to lifestyle interventions is required.

This survey has some strengths and limitations. We achieved a higher than expected response rate from the BCNA Review and Survey Group, which is typically $10 \%$ (email communication with BCNA Review and Survey Group,3 Oct 2017). We were also able to recruit across Australia, with the percentage of respondents from each Australian State and Territory in our study being similar national averages on $\mathrm{BC}$ incidence sourced from the Australian Institute of Health and Welfare cancer data [56]. However, the majority of women from the BCNA Review and Survey Group did not respond, and the demographics of this group are also unclear. Also, the total numbers of women who used CM for weight management were small. These factors limit the validity of our findings.

\section{Conclusion}

We found evidence for high prevalence of use of CMs in a sample of $\mathrm{BC}$ survivors to improve wellbeing and relieve symptoms. The use of CM for weight loss is more limited, most probably due to concerns over lack of evidence for efficacy and other barriers such as financial cost. However, three quarters of women in our sample would be willing to try $\mathrm{CMs}$ such as acupuncture/acupressure, meditation, yoga, and nutritional supplements should there be relevant supporting evidence for efficacy for weight management. Our findings should be interpreted cautiously given the small numbers of women who were using $\mathrm{CM}$ for weight loss, and the low response rate of our survey. Given the burden of weight 
after BC, further research into these modalities is warranted.

\section{Appendix \\ Specific demographic, medical, menopausal and lymphoedema details requested in the survey Demographic characteristics}

State of residence, highest level of education, ethnicity, employment status, relationship status, current age and age at diagnosis were included to describe the characteristics of women.

\section{Medical details}

Women were asked about their diagnosis, treatments received including treatments received to the axilla, the number of lymph nodes removed, whether they had a reconstruction, use of hormonal treatments, menopausal state (at diagnosis and current), presence of other medical conditions and symptoms such as hot flushes and the presence and severity of lymphoedema.

Women were asked to describe the type of breast cancer they were diagnosed with as either "ductal cancer insitu (DCIS)", "localised stage breast cancer (where your breast cancer is contained within your breast and/or lymph nodes), "metastatic breast cancer (breast cancer that has spread beyond the breast tissue and lymph nodes to distant parts of the body, such as the bones, liver and lungs; also called advanced, secondary or stage four)" or "inflammatory breast cancer". For convenience, inflammatory breast cancer and metastatic breast cancer were then combined and referred to as advanced breast cancer. Women were also asked to indicate the treatments they received such as "Lumpectomy alone", "Lumpectomy and radiation", "mastectomy alone", "mastectomy and radiation", "removal of lymph nodes", "chemotherapy", "hormonal therapy", "targeted therapy (Herceptin)", and "other". As chemotherapy is invariably not provided to women with DCIS, we recoded the diagnosis as "localised" if a woman indicated that she had received chemotherapy.

Menopausal state at the time of diagnosis was assessed as either "Premenopausal (regular periods with no menopausal symptoms such as hot flushes)", "Perimenopausal/in the menopausal transition (no periods for at least 2 months, plus hot flushes)", "Postmenopausal (no periods for at least 12 months)" or "Previous surgical menopausal (both ovaries or uterus/womb had been removed)." Participants who indicated they were premenopausal or perimenopausal at the time of diagnosis were asked if they were having periods before breast cancer treatment and to describe what has happened to their periods now; "they have stopped", "they stopped and then started again", "they have become more irregular", "no change" or "other".
Lymphoedema severity was defined as either "no problem (no noticeable swelling)", "mild (soft swelling that is not obvious to others and comes and goes)", "moderate (swelling with occasional hardness in some areas that is obvious to others and is always present)", "severe (profuse swelling with thickened skin, constant hardness, and a very large, heavy arm that is extremely obvious to others and is always present) as described elsewhere [7]."

\section{Lifestyle habits}

Women were asked if they had tried the following specific diets in the previous 12 months: Atkins diet (low carbohydrate), 5:2 diet (eat what you want 5 days a week, send your body into starvation mode for 2 days), Paleolithic diet, Dukan diet (High-protein, low-carb), Vegetarian diet, Vegan diet, Weight Watchers diet, Raw food diet, Ultra low-fat diet, Zone diet, Cambridge diet (very low calories), South Beach diet (low-GI), Other. They were asked if they ate at least the recommended serves of fruit and vegetables a day (2 fruit, five vegetable) with answer options of Yes/No. Self-perceived diet quality was assessed as Excellent/Very Good/Good/Fair/ Poor. Smoking was assessed as current cigarrete use (Never smoked/Ex smoker/Recently quit ex smoker (smoked in the last 3 months)/Current smoker) and current smokers were asked to indicate the number of cigarettes they smoked each day. Alcohol intake was assessed as Non drinker/1-7 standard drinks a week/814 standard drinks a week/>14 standard drinks a week) and a guide to standard drink sizes was provided. The validated Weight Self Efficacy Scale (WEL-SF) [3] was used to evaluate how confident women now felt about being able to successfully resist the desire to overeat in eight different situations on an 11-point Likert scale from 0 (not confident at all) to 10 (very confident). We further dichotomised the responses into "Not confident" (0-4) and "Confident" (5-10). Physical activity levels were calculated according to the number of 20-min sessions of less vigorous exercise or more vigorous exercise a week, given a weighting and described in terms of MET (metabolic cost) minutes where MET minutes less than 80 were coded as no physical activity, 80 to 400 as low, 400 to 560 as moderate and more than 560 as high. A value of 4 METs was given to moderate physical activity and 7.5 to vigorous physical activity [26].

\section{Weight management}

Experiences with a range of weight loss interventions (Exercise, Diet - various: Intermittent fasting, etc. (please specify), Meal replacements e.g. shakes, Medication, Weight loss supplements/products, Surgery (please specify), Online program e.g. 12 week Body Transformation, Social support, Weight loss program e.g. Jenny Craig, Psychological treatments such as CBT (Cognitive 
Behavioural Therapy) and the perceived effectiveness of the interventions on was described using a five-point Likert scale from 1 (not at all effective) to 5 (very effective). The responses were further dichotomized into 1 to 2 (not effective) and 3 to 5 (effective). Women were also asked about perceived barriers and facilitators to successful weight loss and weight maintenance, and what they believed should be research priorities in this area.

\section{Abbreviations}

BC: Breast Cancer; BCNA: Breast Cancer Network Australia; BMI: Body Mass Index; CM: Complementary Medicine; DCIS: Ductal Carcinoma In Situ; GP: General Practitioner

\section{Acknowledgements}

We thank the consumer representatives from Breast Cancer Network Australia who provided feedback on the survey instrument used in this study; Natalie Zakhary who assisted with formatting the online survey; Kellie Stalgis-Bilinski who provided early feedback on the survey; and Karen Monaghan who assisted with data cleaning.

Participants in this research were recruited from Breast Cancer Network Australia's (BCNA) Review and Survey Group, a national, online group of Australian women living with breast cancer who are interested in receiving invitations to participate in research. We acknowledge the contribution of the women involved in the Review and Survey Group who participated in this project.

\section{Authors' contributions}

CE conceived of the study, designed the survey instrument, and collected the data. JB contributed to design of the survey instrument and study. AEC led the data analysis. DN contributed significantly to interpretation of the data, drafting of the manuscript, and critical revision for important intellectual content. CE, AEC, JB and DN contributed significantly to the interpretation of the data, drafting the manuscript, critical revision of the manuscript for important intellectual content, and provided final approval for publication.

\section{Funding}

This study did not receive any funding. CE is supported by an endowment from the Jacka Foundation of Natural Therapies.

\section{Availability of data and materials}

The datasets used and/or analysed during the current study are available from the corresponding author on reasonable request.

\section{Ethics approval and consent to participate}

Consent was implied upon commencing the online anonymous survey. Ethics approval was provided by the Human Research Ethics Committee, Western Sydney University (H12444, Oct 2017).

\section{Consent for publication}

Not applicable.

\section{Competing interests}

CE declares that she is a practising GP and acupuncturist and the Director of an integrative healthcare centre, and that, as a medical research institute, NICM Health Research Institute receives research grants and donations from foundations, universities, government agencies, and industry. Sponsors and donors provide untied and tied funding for work to advance the vision and mission of the Institute.

\section{Author details}

'NICM Health Research Institute, Western Sydney University, Locked Bag 1797, Penrith, NSW 2751, Australia. ${ }^{2}$ Department of Clinical Medicine, Faculty of Medicine and Health Science, Macquarie University, Sydney, NSW 2109, Australia.
Received: 16 August 2019 Accepted: 7 November 2019

Published online: 21 November 2019

\section{References}

1. NCCAM. Expanding Horizons of Healthcare: Five-Year Strategic Plan 20052009. Washington DC: U.S Department of Health and Human Services; 2004

2. Zollman C, Vickers A. What is complementary medicine? BMJ. 1999; 319(7211):693

3. Wanchai A, Armer JM, Stewart BR. Complementary and alternative medicine use among women with breast cancer: a systematic review. Clin J Oncol Nurs. 2010;14(4):E45-55.

4. Astin JA, Reilly C, Perkins C, Child WL. Breast cancer patients' perspectives on and use of complementary and alternative medicine: a study by the Susan G. Komen breast Cancer Foundation. J Soc Integr Oncol. 2006;4(4):157-69.

5. Tautz E, Momm F, Hasenburg A, Guethlin C. Use of complementary and alternative medicine in breast cancer patients and their experiences: a cross-sectional study. Eur J Cancer. 2012;48(17):3133-9.

6. Vance $V$, Mourtzakis M, McCargar L, Hanning R. Weight gain in breast cancer survivors: prevalence, pattern and health consequences. Obes Rev. 2011;12(4):282-94.

7. Saquib N, Flatt SW, Natarajan L, Thomson CA, Bardwell WA, Caan B, Rock CL Pierce JP. Weight gain and recovery of pre-cancer weight after breast cancer treatments: evidence from the women's healthy eating and living (WHEL) study. Breast Cancer Res Treat. 2007:105(2):177-86.

8. Qualtrics: Qualtrics. In. Provo, Utah, USA; 2018.

9. World Health Organisation. Obesity: Preventing and Managing the Global Epidemic, Report of a WHO consultation. Geneva: World Health Organisation; 2000.

10. Quandt SA, Verhoef MJ, Arcury TA, Lewith GT, Steinsbekk A, Kristoffersen AE, Wahner-Roedler DL, Fønnebø V. Development of an international questionnaire to measure use of complementary and alternative medicine (I-CAM-Q). J Altern Complement Med. 2009:15(4):331-9.

11. IBM Corp. IBM SPSS Statistics for Windows. 23 edn. Armonk: IBM Corp; 2015.

12. StataCorp. Stata Statistical Software Series 13: Release 13. 13 edn. College Station: StataCorp LP; 2013

13. Kremser T, Evans A, Moore A, Luxford K, Begbie S, Bensoussan A, Marigliani $\mathrm{R}$, Zorbas $\mathrm{H}$. Use of complementary therapies by Australian women with breast cancer. Breast. 2008;17(4):387-94.

14. Nurfaizah Saibul ZMS, Rahmat A, Sulaiman S, Yaw YH. Use of Complementary and Alternative Medicine among Breast Cancer Survivors. Asian Pac J Cancer Prev. 2012:13:4081-6.

15. Boon H, Brown JB, Gavin A, Kennard MA, Stewart M. Breast Cancer survivors' perceptions of complementary/alternative medicine (CAM): making the decision to use or not to use. Qual Health Res. 1999;9(5):639-53.

16. Cui Y, Shu XO, Gao Y, Wen W, Ruan ZX, Jin F, Zheng W. Use of complementary and alternative medicine by chinese women with breast cancer. Breast Cancer Res Treat. 2004:85(3):263-70.

17. Crocetti E, Crotti N, Feltrin A, Ponton P, Geddes M, Buiatti E. The use of complementary therapies by breast cancer patients attending conventional treatment. Eur J Cancer. 1998;34(3):324-8.

18. Amariles P, Gonzalez LI, Giraldo NA. Prevalence of self-treatment with complementary products and therapies for weight loss: a randomized cross-sectional study in overweight and obese patients in Colombia. Curr Ther Res Clin Exp. 2006;67(1):66-78.

19. Akilen R, Pimlott Z, Tsiami A, Robinson N. The use of complementary and alternative medicine by individuals with features of metabolic syndrome. J Integr Med. 2014;12(3):171-4

20. Zhang RQ, Tan J, Li FY, Ma YH, Han LX, Yang XL. Acupuncture for the treatment of obesity in adults: a systematic review and meta-analysis. Postgrad Med J. 2017;93(1106):743-51.

21. Richards D, Marley J. Stimulation of auricular acupuncture points in weight loss. Aust Fam Physician. 1998;27(Suppl 2):S73-7.

22. Li H, Zhang JB, Xu C, Tang QQ, Shen WX, Zhou JZ, Chen JD, Wang YP. Effects and mechanisms of auricular vagus nerve stimulation on high-fatdiet--induced obese rats. Nutrition. 2015;31(11-12):1416-22.

23. Firouzjaei A, Li GC, Wang N, Liu WX, Zhu BM. Comparative evaluation of the therapeutic effect of metformin monotherapy with metformin and acupuncture combined therapy on weight loss and insulin sensitivity in diabetic patients. Nutr Diabetes. 2016;6:e209. 
24. Gucel F, Bahar B, Demirtas C, Mit S, Cevik C. Influence of acupuncture on leptin, ghrelin, insulin and cholecystokinin in obese women: a randomised, sham-controlled preliminary trial. Acupunct Med. 2012;30(3):203-7.

25. Hsu CH, Wang CJ, Hwang KC, Lee TY, Chou P, Chang HH. The effect of auricular acupuncture in obese women: a randomized controlled trial. J Women's Health. 2009;18(6):813-8.

26. Lin RT, Tzeng CY, Lee YC, Chen Yl, Hsu TH, Lin JG, Chang SL. Acupointspecific, frequency-dependent, and improved insulin sensitivity hypoglycemic effect of electroacupuncture applied to drug-combined therapy studied by a randomized control clinical trial. Evid Based Complement Alternat Med. 2014;2014:371475.

27. Lin RT, Chen CY, Tzeng CY, Lee YC, Cheng YW, Chen Yl, Ho WJ, Cheng JT, Lin JG, Chang SL. Electroacupuncture improves glucose tolerance through cholinergic nerve and nitric oxide synthase effects in rats. Neurosci Lett. 2011:494(2):114-8

28. Lin RT, Tzeng CY, Lee YC, Ho WJ, Cheng JT, Lin JG, Chang SL. Acute effect of electroacupuncture at the Zusanli acupoints on decreasing insulin resistance as shown by lowering plasma free fatty acid levels in steroidbackground male rats. BMC Complement Altern Med. 2009;9:26.

29. Liang F, Koya D. Acupuncture: is it effective for treatment of insulin resistance? Diabetes Obes Metab. 2010;12(7):555-69.

30. Peplow PV, Baxter GD. Electroacupuncture for control of blood glucose in diabetes: literature review. J Acupunct Meridian Stud. 2012;5(1):1-10.

31. Wang F, Tian DR, Han JS. Electroacupuncture in the treatment of obesity. Neurochem Res. 2008;33(10):2023-7.

32. Sniezek DP, Siddiqui IJ. Acupuncture for treating anxiety and depression in women: a clinical systematic review. Med Acupunct. 2013;25(3):164-72.

33. Mazzoni R, Mannucci E, Rizzello SM, Ricca V, Rotella CM. Failure of acupuncture in the treatment of obesity: a pilot study. Eat Weight Disord. 1999;4(4):198-202.

34. Witt CM, Pach D, Brinkhaus B, Wruck K, Tag B, Mank S, Willich SN. Safety of acupuncture: results of a prospective observational study with 229,230 patients and introduction of a medical information and consent form. Forschende Komplementarmedizin. 2009:16(2):91-7.

35. White A: A cumulative review of the range and incidence of significant adverse events associated with acupuncture. 2004. (0964-5284 (Print)).

36. MacPherson $H$, Thomas K, Walters S, Fitter M. A prospective survey of adverse events and treatment reactions following 34,000 consultations with professional acupuncturists. Acupunct Med. 2001;19(2):93-102.

37. Ben-Horin I, Kahan P, Ryvo L, Inbar M, Lev-Ari S, Geva R. Acupuncture and reflexology for chemotherapy-induced peripheral neuropathy in breast Cancer. Integr Cancer Ther. 2017;16(3):258-62.

38. Chien TJ, Liu CY, Chang YF, Fang CJ, Hsu CH. Acupuncture for treating aromatase inhibitor-related arthralgia in breast cancer: a systematic review and meta-analysis. J Altern Complement Med. 2015;21(5):251-60.

39. Hershman DL, Unger JM, Greenlee H, Capodice JL, Lew DL, Darke AK, Kengla AT, Melnik MK, Jorgensen CW, Kreisle WH, et al. Effect of acupuncture vs sham acupuncture or waitlist control on joint pain related to aromatase inhibitors among women with early-stage breast Cancer: a randomized clinical trial. Jama. 2018;320(2):167-76.

40. Chien TJ, Hsu CH, Liu CY, Fang CJ. Effect of acupuncture on hot flush and menopause symptoms in breast cancer- a systematic review and metaanalysis. PLoS One. 2017;12(8):e0180918.

41. Zhang X, Wang X, Zhang B, Yang S, Liu D. Effects of acupuncture on breast cancer-related lymphoedema: a systematic review and meta-analysis of randomised controlled trials. Acupunct Med. 2019;37(1):16-24.

42. Carriere K, Khoury B, Gunak MM, Knauper B. Mindfulness-based interventions for weight loss: a systematic review and meta-analysis. Obes Rev. 2018;19(2):164-77.

43. Katterman SN, Kleinman BM, Hood MM, Nackers LM, Corsica JA. Mindfulness meditation as an intervention for binge eating, emotional eating, and weight loss: a systematic review. Eat Behav. 2014;15(2):197-204.

44. Noordali F, Cumming J, Thompson JL. Effectiveness of mindfulness-based interventions on physiological and psychological complications in adults with diabetes: a systematic review. J Health Psychol. 2017;22(8):965-83.

45. Olson KL, Emery CF. Mindfulness and weight loss: a systematic review. Psychosom Med. 2015;77(1):59-67.

46. Rogers JM, Ferrari M, Mosely K, Lang CP, Brennan L. Mindfulness-based interventions for adults who are overweight or obese: a meta-analysis of physical and psychological health outcomes. Obes Rev. 2017;18(1):51-67.
47. Ruffault A, Czernichow S, Hagger MS, Ferrand M, Erichot N, Carette C, Boujut $E$, Flahault $C$. The effects of mindfulness training on weight-loss and healthrelated behaviours in adults with overweight and obesity: a systematic review and meta-analysis. Obes Res Clin Pract. 2017;11(5 Suppl 1):90-111.

48. Chung S, Zhu S, Friedmann E, Kelleher C, Kozlovsky A, Macfarlane KW, Tkaczuk KH, Ryan AS, Griffith KA. Weight loss with mindful eating in African American women following treatment for breast cancer: a longitudinal study. Support Care Cancer. 2016;24(4):1875-81.

49. Thomas EA, Mijangos JL, Hansen PA, White S, Walker D, Reimers C, Beck AC, Garland EL. Mindfulness-oriented recovery enhancement restructures reward processing and promotes interoceptive awareness in overweight Cancer survivors: mechanistic results from a stage 1 randomized controlled trial. Integr Cancer Ther. 2019;18:1534735419855138.

50. Lauche R, Langhorst J, Lee MS, Dobos G, Cramer H. A systematic review and meta-analysis on the effects of yoga on weight-related outcomes. Prev Med. 2016;87:213-32.

51. Littman AJ, Bertram LC, Ceballos R, Ulrich CM, Ramaprasad J, McGregor B, McTiernan A. Randomized controlled pilot trial of yoga in overweight and obese breast cancer survivors: effects on quality of life and anthropometric measures. Support Care Cancer. 2012;20(2):267-77.

52. Namazi N, Larijani B, Ayati MH, Abdollahi M. The effects of Nigella sativa L. on obesity: a systematic review and meta-analysis. J Ethnopharmacol. 2018; 219:173-81

53. Namazi N, Larijani B, Azadbakht L. Alpha-lipoic acid supplement in obesity treatment: A systematic review and meta-analysis of clinical trials. Clin Nutr. 2018;37(2):419-28

54. Pooyandjoo M, Nouhi M, Shab-Bidar S, Djafarian K, Olyaeemanesh A. The effect of (L-)carnitine on weight loss in adults: a systematic review and meta-analysis of randomized controlled trials. Obes Rev. 2016;17(10):970-6.

55. Zhang YB, Chen WH, Guo JJ, Fu ZH, Yi C, Zhang M, Na XL. Soy isoflavone supplementation could reduce body weight and improve glucose metabolism in non-Asian postmenopausal women--a meta-analysis. Nutrition. 2013:29(1):8-14.

56. Australian Institute of Health and Welfare (AlHW). Cancer Data in Australia. Canberra: AlHW; 2018

\section{Publisher's Note}

Springer Nature remains neutral with regard to jurisdictional claims in published maps and institutional affiliations.

Ready to submit your research? Choose BMC and benefit from:

- fast, convenient online submission

- thorough peer review by experienced researchers in your field

- rapid publication on acceptance

- support for research data, including large and complex data types

- gold Open Access which fosters wider collaboration and increased citations

- maximum visibility for your research: over $100 \mathrm{M}$ website views per year

At $\mathrm{BMC}$, research is always in progress.

Learn more biomedcentral.com/submission 